\title{
ОСОБЕННОСТИ ПОДГОТОВКИ БУДУЩИХ УЧИТЕЛЕЙ
} ИНФОРМАТИКИ

\section{FEATURES OF TRAINING FUTURE TEACHERS OF INFORMATICS}

I. Dukhovnikova

A. Korol

Summary: The article is devoted to the peculiarities of training future teachers of informatics. The relevance of the article is due to the importance of teaching computer science and ICT, the need to fill out electronic diaries, distance education, teach schoolchildren to use a computer, work with information networks and databases. The scientific novelty of the work lies in the fact that it summarizes the current legislative acts in the field of teaching informatics, characterizes the stages of education for informatics teachers and proposes new ways to resolve the contradictions between the methodological base of higher educational institutions and the requirements for a teacher in a high-tech information society.

Keywords: informatics teacher, future teacher training, informatics and ICT, high-tech information society.

\author{
Духовникова Ирина Юрьевна \\ старший преподаватель, ФГБОУ ВО "Тихоокеанский \\ государственный университет", г. Хабаровск \\ 009657@pnu.edu.ru \\ Король Александр Михайлович \\ к.n.н., профессор, ФГБОУ ВО "Тихоокеанский \\ государственный университет", г. Хабаровск \\ kor_kor2001@mail.ru
}

Аннотация: Статья посвящена особенностям подготовки будущих учителей информатики. Актуальность статьи обусловлена важностью преподавания информатики и ИКТ, необходимостью заполнения электронных дневников, дистанционного образования, обучения школьников устройства компьютера, работе с информационными сетями и базами данных. Научная новизна работы заключается в том, что в ней обобщается действующие законодательные акты в области преподавания информатики, характеризуются две ступени образования учителя информатики и предлагаются новые способы решения противоречий между методологической базой высших учебных заведений и требованиям, предъявляемым к учителю в условиях высокотехнологичного информационного общества.

Ключевые слова: учитель информатики, подготовка будущих учителей, информатика и ИКТ, высокотехнологичное информационное общество.

школе, а также преподавателями высших учебных заведений, ведущих профориентационную работу.

Прежде чем перейти к особенностям профессиональной подготовки учителей информатики необходимо отметить значение «Информатики и ИКТ», представленное в законодательстве Российской Федерации. В соответствии с Приказом Министерства образования и науки РФ от 17.12.2010 № 1897 «Об утверждении федерального государственного образовательного стандарта основного общего образования» изучение информатики в школе необходимо для развития логического мышления обучающихся, осознания и понимания информационных процессов в жизни общества, а также научиться применять полученные знания в реальной жизни [2].

Результатами усвоения школьного курса «Информатика» и соответственно требованиями, предъявляемыми к содержанию обучения, являются следующие:

1. усвоение вклада информатики в становление научной картины мира;

2. умение работать с поисковыми системами и базами данных;

3. знание одного из языков программирования;

4. знание устройства современного компьютера, умение работать с компьютерными сетями, навык обеспечения функционирования системы ИКТ [3]. 
При рассмотрении действующего законодательства, регламентирующего деятельность учителя информатики, необходимо отметить значимость изучения предмета «Информатика» и знакомства с информационными системами, информационными сетями, программным обеспечением и базами данных. Кроме этого, следует обратить внимание на тесную взаимосвязь математики, алгебры и геометрии с информатикой, что способствует формированию логического мышления обучающихся, а также пониманию роли информационных процессов в жизни общества. Кроме этого, в современной школе должна быть реализована информационно-образовательная среда, обеспечивающая информационно-методическую поддержку образовательного процесса, планирование и организацию образовательного процесса, использование современных процедур создания, поиска, сбора и обработки, хранения и передачи информации, дистанционного взаимодействия всех участников образовательного процесса с применением дистанционных технологий [3].

Требования, предъявляемые к учителю информатики, должны учитываться в профессиональной подготовке педагога. Поэтапное становление учителя информатики и его знакомство с профессией представлено в табл. 1.

Особое внимание следует уделить рассмотрению предмета «Теория и методика обучения информатики», который является важнейшим компонентом подготовки современного учителя. В рабочей программе дисциплины «Методика обучения и воспитания (информатика) направления подготовки 44.03.01 на изучении предмета выделяется 504 академических часа. Студентам предлагается изучение целей и задач введения в школу предмета «Информатика», содержания и стандартизации школьного образования в области информатики, организации обучения информатики в школе, этапов и уровней обучения информатики, информационных процессов, методических рекомендаций обучения устройства и функционирования компьютера, алгоритмизации и программирования и др.
При обучении в магистратуре (направление подготовки 44.04.01) студентам предлагается изучение теории и методики обучения информатике младших школьников, теории и методики обучения информатики в средней школе, теории и методике обучения информатики в старшей школе (базовый и углубленный уровень).

Однако как отмечает О.В. Садыкова, существующая практика в современной системе образования не может полностью охватить все компоненты науки «Информатика» [4, с. 281]. Поэтому объем и глубина соответствующих дисциплин с учетом сокращения количества учебных часов не в полной мере отражает уровень науки «Информатика» на современном этапе. В связи с этим, возникает необходимость повышения квалификации на базе высших учебных заведений. Исследователь Т.А. Шастун считает, что современная подготовка учителей информатики не соответствует постоянному увеличению образовательного потенциала «Информатики и ИКТ», что свидетельствует о возрастании требований к преподавателю и овладению специально-технологическими компетенциями, что не соотносится с устаревшей методологической базой в вузе [5, с. 84].

Исследователи Т.Б. Захарова и А.С. Захаров считают, что при организации учебного процесса по освоению дисциплины «Методика преподавания информатики» необходимо увеличить количество практических работ, интерактивных семинарских занятий, проведению деловых и ролевых игр, выполнению исследовательских проектов с использованием мультимедийных технологий [1, c. 78].

Поэтому в рамках практических занятий студентам необходимо разбирать педагогические ситуации, которые могут возникнуть на уроке информатики в школе, научиться их успешно решать, организовать встречи учителей информатики со студентами высших учебных заведений с возможностью передачи знаний и опыта, а также разбора наиболее частных вопросов, касающихся преподавания. В рамках научных конференций, необходимо организовать встречи с составителями учебников

Подготовка будущих учителей информатики

\begin{tabular}{|l|l|l|}
\hline Критерий & $\begin{array}{l}\text { 44.03.01 Педагогическое образование. } \\
\text { Профиль: Информатика и ИКТ }\end{array}$ & $\begin{array}{l}\text { 44.04.01 Педагогическое образование. Информатика } \\
\text { в общем и дополнительном образовании }\end{array}$ \\
\hline Срок обучения & 4 года & 2 года \\
\hline Квалификация & Бакалавр & Магистр \\
\hline Особенность освоения образовательной \\
программы & $\begin{array}{l}\text { Образовательная программа бакалавриата включает } \\
\text { в себя } 60 \text { дисциплин, из них - 24 посвящены изучению } \\
\text { архитектуры компьютера, баз данных и системы баз } \\
\text { данных, геоинформационных технологий, инфоком- } \\
\text { муникационных систем и технологий, информацион- } \\
\text { ных систем и проч. }\end{array}$ & \begin{tabular}{l} 
Пе явлются профильными. \\
\hline
\end{tabular} \\
\hline
\end{tabular}


по информатике, специалистов в области методики преподавания информатики с обсуждением актуальных вопросов в области информационных технологий.

Мы рассмотрели две ступени подготовки учителей информатики в современной школе. Необходимо отметить, что с каждым годом возрастают требования, предъявляемые к преподавателю информатики и ИКТ. Это связано с тем, что в связи с необходимостью дистанционного образования, заполнением и проверкой электронных дневников, созданием и разработкой ис- следовательских проектов возрастает важность предмета «Информатика и ИКТ» в школе.

Таким образом, учителю информатики необходимо подготовить выпускника школы к работе в условиях высокотехнологичного информационного общества. Для этого учителю информатики необходимо постоянно повышать свою классификацию и проходить учебные курсы, несмотря на насыщенность образовательной программы и возможность освоения двух ступеней образовательной деятельности.

\section{ЛИТЕРАТУРА}

1. Захарова Т.Б., Захаров А.С. Роль и место дисциплины «Методика обучения информатики» в подготовке будущего учителя информатики // Преподаватель XXI век. 2015. № 4. С. 75-86.

2. Приказ Министерства образования и науки РФ от 17.05.2012 г. № 413 (ред. от 11.12.2020) «06 утверждении федерального государственного образовательного стандарта среднего общего образования» [Электронный ресурc]. URL: https://docs.cntd.ru/document/902350579 (дата 0бращения: 30.07.2021).

3. Приказ Министерства образования и науки РФ от 17.12.2010 г. № 1897 (ред. от 11.12.2020) «06 утверждении федерального государственного образовательного стандарта основного общего образования» [Электронный ресурс]. URL: https://docs.cntd.ru/document/902350579 (дата 0бращения: 30.07 .2021 ).

4. Садыкова 0.В. Методические подходы формирования проектировочного компонента профессиональных компетенций будущих учителей информатики // Современные исследования социальных проблем. 2017. № 4-2. С. 280-283.

5. Шастун Т.А. Формирование специально-технологических компетенций учителя информатики в вузе // Крымский научный вестник. 2017. № 2-3. С. 83-93.

$$
\text { (с Духовникова Ирина Юрьевна (009657@pnu.edu.ru), Король Александр Михайлович (kor_kor2001@mail.ru). }
$$

Журнал «Современная наука: актуальные проблемы теории и практики»

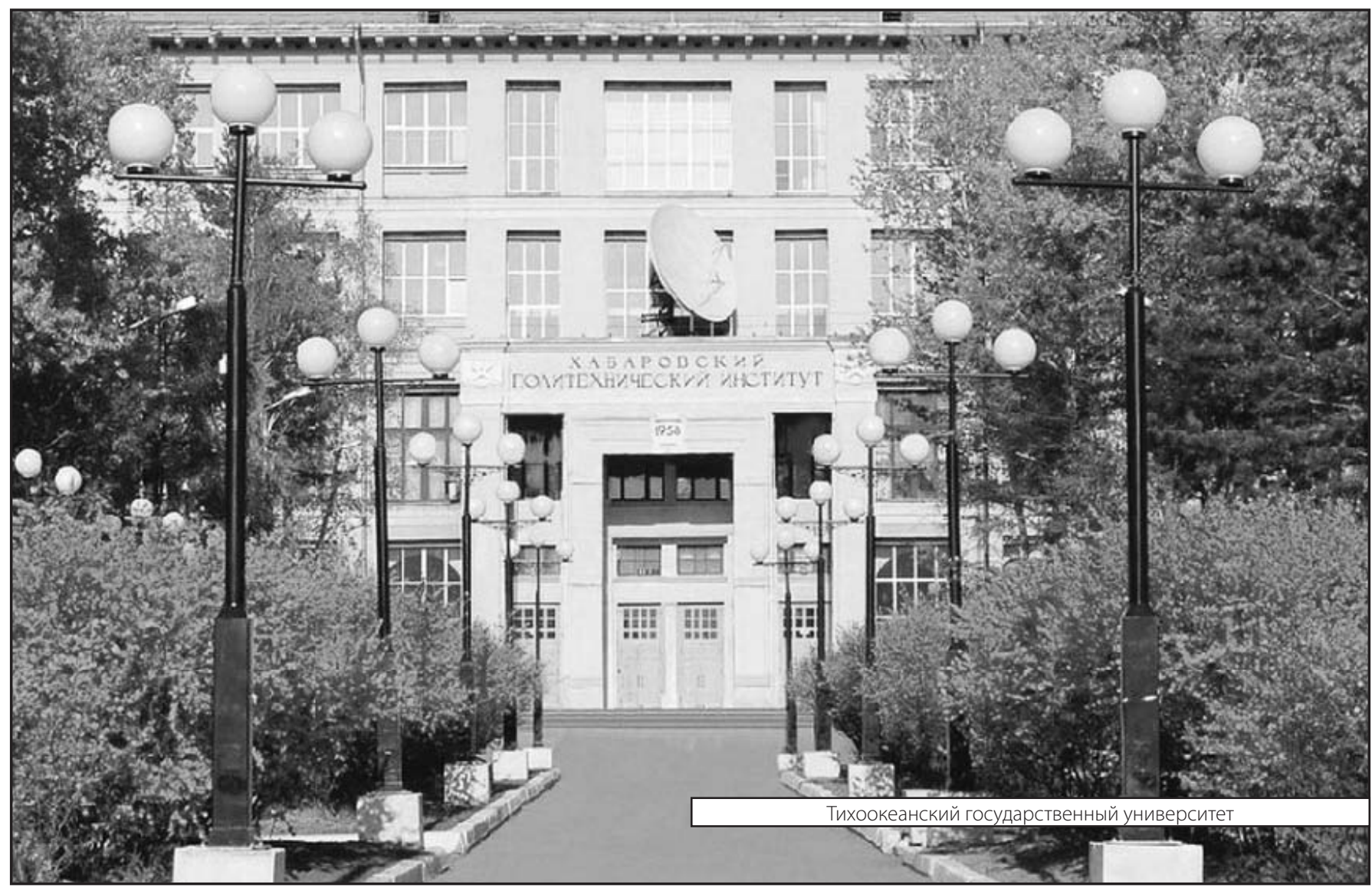

